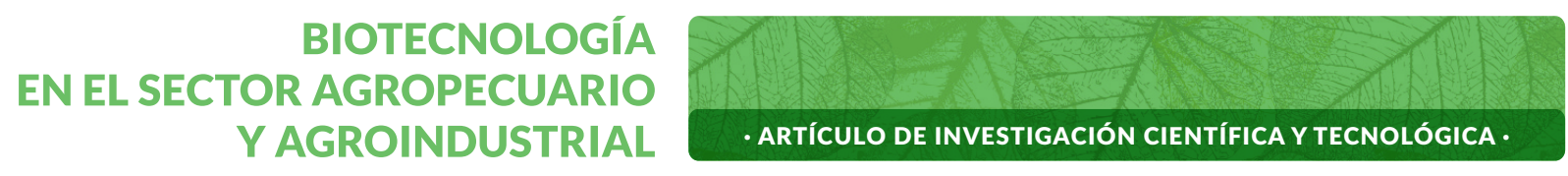

\title{
Efecto microbiológico de recubrimiento modificado por vía ácida sobre el tomate larga vida*
}

\section{Microbiological effect of coating modified by acid via on the long tomato life}

\section{Efeito microbiológico do revestimento de ácido amplificado na vida de longo tomate}

\author{
NELSY HOYOS-YELA ${ }^{1}$, ROCÍO PÉREZ-IMBACHÍ2, SANDRA PATRICIA PAZ-PEÑA ${ }^{3}$, \\ SILVIO ANDRÉS MOSQUERA-SÁNCHEZ ${ }^{4}$
}

Historial del Artículo

Recibido para evaluación: 22 de Mayo 2019.

Aprobado para publicación: 1 de Mayo 2020.

* Proyecto de investigación de origen: "Efecto de la aplicación de un recubrimiento de almidón de yuca modificado por vía ácida sobre el tomate larga vida (Solanum lycopersicum). Financiación: Universidad del Cauca. Culminado el 22 de febrero de 2017.

1 Universidad del Cauca, Facultad de Ciencias Agrarias, Grupo Ciencia y Tecnología de Biomoléculas de Interés Agroindustrial (CYTBIA). Ingeniera Agroindustrial. Popayán, Colombia. https://orcid.org/0000-0002-9854-473X

2 Universidad del Cauca, Facultad de Ciencias Agrarias, Grupo Ciencia y Tecnología de Biomoléculas de Interés Agroindustrial (CYTBIA). Ingeniera Agroindustrial. Popayán, Colombia. https://orcid.org/0000-0001-7913-6004

3 Universidad del Cauca, Facultad de Ciencias Agrarias, Grupo Ciencia y Tecnología de Biomoléculas de Interés Agroindustrial (CYTBIA). Ingeniera Agroindustrial. Popayán, Colombia. https://orcid.org/0000-0002-2448-608X

4 Universidad del Cauca, Facultad de Ciencias Agrarias, Grupo Ciencia y Tecnología de Biomoléculas de Interés Agroindustrial (CYTBIA). M.Sc. Ingeniería. Popayán, Colombia. https://orcid.org/0000-0002-7899-854X

Correspondencia: silvioandres@gmail.com 


\section{RESUMEN}

Se aplicó un recubrimiento elaborado con almidón de yuca modificado por vía ácida, para evaluar el comportamiento pos-cosecha del tomate bajo condiciones ambientales, determinando su efecto sobre las características estructurales del tomate y su acción microbiológica sobre los hongos Colletotrichum sp y Fusarium Sp. La modificación de almidón nativo de yuca variedad SM 707-17 se realizó por adición de ácido cítrico (15\% p/p respecto al almidón en base seca) a una suspensión de almidón sometida a condiciones controladas de temperatura y velocidad de agitación. El efecto se comparó con el de la aplicación de otros elaborados con base en almidón modificado enzimáticamente y almidón nativo, siendo T1: muestra testigo; T2: recubrimiento con almidón modificado enzimáticamente; T3: recubrimiento con almidón modificado con ácido cítrico y T4: recubrimiento con almidón nativo. La aplicación se realizó de forma manual con esponja limpia y estéril; los tomates se colocaron en bandejas rotuladas dejando secar por $24 \mathrm{~h}$ a temperatura ambiente, a partir de las cuales se inició la medición de las variables crecimiento microbiano y caracterización microscópica del exocarpo del tomate durante 15 días, aplicando un diseño factorial completamente al azar $4 \times 6$, que tuvo en cuenta el tipo de muestras relacionadas e independientes; los datos obtenidos se analizaron mediante el software SPSS versión 19 con el cual se encontró que el factor "Recubrimiento" no influyó sobre las variables de respuesta analizadas, a diferencia del factor "Tiempo" que tuvo efecto decisivo sobre las mismas.

\section{SUMMARY}

A coating elaborated with modified cassava starch was applied by acid route, to evaluate the post-harvest behavior of the tomato under environmental conditions, determining its effect on the microbiological and structural characteristics. The modification of native starch of cassava variety SM 707-17 was carried out by addition of citric acid (15\% w/w with respect to starch on dry basis) to a suspension of starch subjected to controlled conditions of temperature and speed of agitation. The effect was compared with that of the application of others elaborated based on enzymatically modified starch and native starch, being T1: control sample; T2: coating with enzymatically modified starch; T3: coating with starch modified with citric acid and T4: coating with native starch. The application was made manually with clean and sterile sponge; The tomatoes were placed in labeled trays, allowing to dry for $24 \mathrm{~h}$ at room temperature, from which the microbial growth and microscopic characterization of the tomato exocarp was measured for 15 days, applying a completely randomized $4 \times 6$ factorial design that had consider the type of related and independent samples; the data obtained were analyzed using SPSS software version 19, which found that the "Coating" factor did

Cómo citar este artículo: NESLY HOYOS-YELA, ROCÍO PÉREZ-IMBACHÍ, SANDRA PATRICIA PAZ-PEÑA, SILVIO ANDRÉS MOSQUERA-SÁNCHEZ. Efecto microbiológico de recubrimiento modificado por vía ácida sobre el tomate larga vida. Revista Biotecnología en el Sector Agropecuario y Agroindustrial,18(2),2020.145-155, DOI:http://dx.doi.org/10.18684/BSAA(18)145-155

\section{PALABRAS CLAVE:}

Solanum lycopersicom, Almidón de yuca, Ácido cítrico.

\section{KEYWORDS:}

Solanum lycopersicom, Cassava starch, Citrus acid.

\section{PALAVRAS CHAVE:}

Solanum lycopersicom, Amido de mandioca, Ácido cítrico. 
not influence the response variables analyzed, unlike the "Time" factor that had a decisive effect on them.

\section{RESUMO}

Um revestimento elaborado com fécula de mandioca modificada foi aplicado por via ácida, para avaliar o comportamento pós-colheita do tomate sob condições ambientais, determinando seu efeito sobre as características microbiológicas e estruturais. A modificação do amido nativo da variedade de mandioca SM 707-17 foi realizada pela adição de ácido cítrico (15\% p/p em relação ao amido em base seca) a uma suspensão de amido submetida a condições controladas de temperatura e velocidade de agitação. O efeito foi comparado com o da aplicação de outros elaborados com base em amido enzimaticamente modificado e amido nativo, sendo T1: amostra controle; T2: revestimento com amido enzimaticamente modificado; T3: revestimento com amido modificado com ácido cítrico e T4: revestimento com amido nativo. A aplicação foi feita manualmente com esponja limpa e estéril; Tomates foram colocados em bandejas rotuladas deixado a secar durante $24 \mathrm{~h}$ à temperatura ambiente, a partir do qual as variáveis de medição do crescimento microbiano e microscópica tomate caracterização exocarp começou durante 15 dias, usando um desenho factorial $4 \times 6$ completamente casualizado que tinha considerar o tipo de amostras relacionadas e independentes; os dados obtidos foram analisados no software SPSS versão 19 , que constatou que o fator "Coating" não influenciou as variáveis de resposta analisadas, diferentemente do fator "Time" que teve efeito decisivo sobre elas.

\section{INTRODUCCIÓN}

El tomate es la hortaliza de mayor consumo en Colombia y abastece el $59 \%$ de la población [1], su vida útil está entre 7 y 10 días en condiciones de almacenamiento de $10-12,5^{\circ} \mathrm{C}$ y $90-95 \%$ de Humedad Relativa, aunque tiende a deshidratarse por ser climatérico. La maduración está acompañada por cambios en el sabor, color, aroma, textura y pérdida de firmeza debido a cambios físicos y químicos asociados con la degradación de la pared celular y la solubilización de las pectinas por las enzimas pectinesterasa (PE), poligalacturonasa (PG) y pectatoliasa (PL) [2]. Debido a su manipulación constante e inapropiada desde el momento de cosecha por el empleo de canastillas plásticas para recolección y transporte, pasando por la selección, clasificación y almacenamiento ocurre contaminación del producto (materiales, cantidad, sobre amontonamiento, etc.) y la aparición de magulladuras, abrasiones, impactos, cortaduras, ataque de insectos que favorecen la aparición de enfermedades causadas por hongos y bacterias tales como Alternaria, Botrytis, Diploidia, Monilia, Penicillium, Phomopsis, Rhizophus, Erwinia y Pseudomonas. Debido a los innumerables elementos que ocasionan pérdidas de calidad, se están generando y usando técnicas y tecnologías pos-cosecha para retrasar la senescencia y mantener la calidad del producto durante un mayor tiempo, como por ejemplo la aplicación de recubrimientos.

Teniendo en cuenta el creciente interés por consumir productos naturales más sanos, seguros y respetuosos con el medio ambiente, se están desarrollando recubrimientos naturales que crean una barrera semipermeable a gases y al vapor de agua al crear una atmósfera modificada que reduce la velocidad de respiración y deshidratación, además de permitir la incorporación de aditivos alimentarios que retardan la aparición de desórdenes fisiológicos [3]. Los recubrimientos deben ser transparentes, estar exentos de sabores, olores extraños, sustancias nocivas para la salud, estables a distintas condiciones de almacenamiento, ser extensibles para que el alimento quede recubierto de forma homogénea y ofrecer resistencia a daños mecánicos leves [4].

El almidón es un componente alimentario utilizado en el mejoramiento de propiedades funcionales y como solución de recubrimiento a partir de materiales como maíz (Zea mays) y yuca (Manihot esculenta Crantz), entre otros. Las limitaciones del almidón nativo disminuyen su funcionalidad por el grado de ramificación, la relación amilosa-amilopectina, distribución del peso molecular, condiciones de $\mathrm{pH}$, temperatura y presión aplicadas, que afectan las propiedades mecánicas, térmicas, estructurales y de barrera, como la disminución de la resistencia a esfuerzos de corte, descomposición térmica, alto nivel de retrogradación y sinéresis [5]. Por esta razón, se realiza la modificación de sus propiedades por vía química, física o biológica como reticulado (cross-linking) con fosfatos o adipatos, pregelatinización, dextrinación o hidrólisis ácida [6].

Los ácidos orgánicos son utilizados como reguladores de acidez, agentes antimicrobianos o modificadores químicos de propiedades funcionales del almidón; el ácido cítrico actúa como promotor de enlaces cruzados (reticulación) entre las cadenas y mejora las 
propiedades mecánicas [7]. Se usó el ácido en la evaluación de un recubrimiento comestible con base en agar y ácido cítrico aplicado en papa fresca, logrando mantener las características sensoriales y de calidad del tubérculo, además de reducir la pérdida de agua con respecto a la muestra testigo después de 25 días de almacenamiento [8].

Se evaluó el efecto de la adición de ácido cítrico en las propiedades de tensión y de barrera en películas elaboradas con base en almidón termoplástico de yuca y su posible acción microbiológica sobre dos hongos causantes de daños en el tomate.

\section{MÉTODO}

El proyecto se desarrolló en las instalaciones de la Planta Piloto para el procesamiento de vegetales, Laboratorios de Biotecnología, Reología y Empaques de la Facultad de Ciencias Agrarias de la Universidad del Cauca y en la Unidad de Microscopía Electrónica ubicada en el Museo de Historia Natural, en la ciudad de Popayán, Colombia, a una altitud de 1.738 msnm, temperatura media de $19^{\circ} \mathrm{C}$ y Humedad Relativa (H.R) del $77,75 \%$.

\section{Materiales}

Se usaron tomates larga vida variedad Indaba en grado 4 de madurez, diámetro ecuatorial promedio de $8 \mathrm{~cm}$ y axial de $6 \mathrm{~cm}$, producidos bajo cubierta y cultivados en la finca "El Porvenir" de la vereda Cinco Días, Municipio de Timbío (Cauca), con altura promedio de $1.850 \mathrm{msnm}$, temperatura media entre 16 y $23^{\circ} \mathrm{C}$. Se usó almidón nativo de yuca variedad SM 707-17 proveniente de la rallandería "La Agustina" ubicada en Mondomo (Cauca) y almidón de yuca SM 707-17 modificado enzimáticamente con alpha - amylasa Bacillus amyloliquefaciens Ban 240L (Sigma Aldrich), con grado de modificación del 10\% de Equivalente de Dextrosa (E.D.) [9].

Se requirió ácido cítrico monohidrato grado analítico con pureza del 99,5\%, marca Carlo Herba, para realizar la modificación del almidón de yuca por vía ácida; aceite esencial de limoncillo (Cymbopogon citratus) de grado alimentario, por sus propiedades antimicrobianas y antibacteriales; glicerina como plastificante no volátil de bajo peso molecular que mejora la flexibilidad, manejabilidad y habilidad de extensión del recubrimiento [10]; Tween 80, aditivo alimentario con acción surfactante para facilitar o aumentar la emulsividad, dispersión y adherencia del recubrimiento [11].

\section{MÉTODO}

\section{Modificación del almidón con ácido cítrico}

El almidón en suspensión de $100 \mathrm{~g}$ al 40\% p/p en base seca se hidrató por 1 hora; se midió $\mathrm{pH}$ inicial $(5,5)$ y se llevó a agitación de $175 \mathrm{rpm}$ con temperatura de $52^{\circ} \mathrm{C}$ en el Shaker Thermo Scientific; cuando la suspensión alcanzó los $52^{\circ} \mathrm{C}$, se adicionó ácido cítrico (15\%), nuevamente se midió el pH y se colocó en el shaker a las mismas condiciones durante $14 \mathrm{~h}$. Al finalizar este tiempo se ajustó el pH 5,5 por neutralización con $\mathrm{NaOH} 3 \mathrm{~N}$ y $1 \mathrm{~N}$.

Se transfirieron las suspensiones a tubos falcon para centrifugar a $4500 \mathrm{rpm}$ por $30 \mathrm{~min}$ (establecido por preliminares) y obtener el sobrenadante para medir ED en el espectrofotómetro UV marca SHIMADZU 1800 [5], procedimiento seguido para el almidón con 25\% $\mathrm{p} / \mathrm{p}$ en base seca y las concentraciones de ácido cítrico, evaluando por separado las concentraciones de $\mathrm{NaOH}$.

\section{Acondicionamiento del fruto}

Se seleccionaron tomates larga vida en estado 4 de madurez, redondos, sanos e inocuos, firmes y jugosos, enteros, con apariencia lisa, sin grietas o quemaduras de sol, sin daños mecánicos o producidos por insectos [12], lavados por inmersión en agua potable y desinfección con solución de hipoclorito de sodio a 5 ppm durante 15 minutos y secados con toalla absorbente [4].

\section{Modificación del almidón}

Se obtuvo una suspensión de $100 \mathrm{~g}$ usando $25 \% \mathrm{p} / \mathrm{p}$ de almidón en base seca y ácido cítrico grado analítico al $15 \% \mathrm{p} / \mathrm{p}$ en base seca [13] con ayuda del Shaker Thermo Scientific a $52^{\circ} \mathrm{C}, 175 \mathrm{rpm}$ con tiempo de modificación de 14 horas, luego de 14 horas se centrifugó a 4500 rpm por 30 min, se eliminó el sobrenadante y se secó el almidón en el horno, iniciando con una temperatura de $20^{\circ} \mathrm{C}$, con aumentos progresivos de $5^{\circ} \mathrm{C}$ hasta llegar a $45^{\circ} \mathrm{C}$ (establecido en pruebas preliminares) y humedad de $12 \%$ [14].

\section{Preparación y aplicación del recubrimiento}

Se realizó una pre-mezcla de los componentes del recubrimiento (agua, glicerol, almidón de yuca, acei- 
te esencial, tween 80) a $300 \mathrm{rpm} \mathrm{y} 40^{\circ} \mathrm{C}$, se calentó desde 40 hasta $75^{\circ} \mathrm{C}$ por 10 min hasta la gelatinización del almidón durante 15 min [15].

\section{Crecimiento microbiano}

Se identificaron los especies de hongos que atacan al tomate, realizando 5 aislamientos a partir del fruto contaminado naturalmente, proporcionándole el medio de cultivo. Se cortaron 4 trozos de tejidos de tomate enfermo y sano, de $1 \mathrm{~cm}^{2}$ de área y de $2 \mathrm{~mm}$ de grosor; a cada muestra se le realizaron 4 enjuagues por 1 minuto cada uno, el primero con hipoclorito al $1 \%$, el segundo con etanol al $75 \%$, el tercero y el cuarto con agua destilada estéril. Se secaron en papel absorbente estéril, se sembraron en agar PDA y se incubaron a $25^{\circ} \mathrm{C}$ por dos días; cuando se observó el crecimiento de los hongos se aislaron 4 muestras de cada caja de Petri en PDA, cortando pequeñas muestras del cultivo de aproximadamente $0,25 \mathrm{~mm}^{2}$, que se re sembraron en PDA, iterativamente hasta obtener un cultivo puro [16].

Para medir la estructura de la epidermis del tomate recubierto, se utilizó Microscopio Óptico de Alta Resolución (MOAR) Marca Nikon modelo Microphot y un Microscopio Electrónico de Transmisión (MET) Marca JEOL, modelo JEM 1200EX. Las muestras de $5 \mathrm{~mm}$ de longitud y $1 \mathrm{~mm}$ de grosor se fijaron en glutaraldehído al $6 \%$ y paraformaldehído al $4 \%$ en $\mathrm{Bu}-$ ffer de Fosfato Salino (PBS) [17], con modificaciones.

Se utilizó un diseño factorial $4 \times 6$ completamente al azar, donde los factores fueron "Tipo de recubrimiento" con 4 niveles (tratamientos T1 a T4) y "Tiempo" con 6 niveles (Días 0, 3, 6, 9, 12 y 15) denominados PI, D3, D6, D9, D12, D15, respectivamente.

T1= Muestra Testigo (tomate sin recubrir)

T2= Recubrimiento con almidón de yuca modificado enzimáticamente

T3= Recubrimiento con almidón de yuca modificado con ácido cítrico

T4= Recubrimiento con almidón de yuca nativo.

Se realizaron tres réplicas con cuatro repeticiones por cada tratamiento, tomando 30 unidades experimentales por réplica. Los resultados obtenidos fueron evaluados por pruebas paramétricas (ANOVA), no paramétricas y paramétricas con medidas repetidas; con una probabilidad de 95\% empleando el software SPSS versión 19.

\section{RESULTADOS}

Después del aislamiento, se hizo seguimiento al crecimiento del hongo, observando sus esporas y características específicas macro morfológicas como color, superficie, borde, consistencia, aspecto y desarrollo; también, se caracterizaron los hongos de forma micro morfológica, teniendo en cuenta estructuras reproductivas, presencia de hifas y la formación de esporas, conidias y la forma del micelio que permiten la identificación del hongo que inicia la degradación del fruto.

\section{Características macro morfológicas y descripción microscópica de hongos que inician el deterioro y degradación en el fruto de tomate}

Durante este periodo se evaluó la sintomatología por área afectada en los tomates (Cuadro 1) evidenciando que Colletotrichum sp. causó mayor daño que Fusarium sp., sobre los tejidos del tomate deteriorando el exocarpo, luego en el mesocarpo y con pudrición al final (Día 15) en el endocarpo (Figura 1), apareciendo pequeñas manchas húmedas en el (Día 6), hundidas y de forma circular que se asemejan a las depresiones dejadas por objetos redondos causados por los hongos [16].

En esas colonias crecientes de Colletotrichum sp se denota que parte central se ennegrece y endurece ligeramente debido a los acérvulos negros que se desarrollan por debajo de la epidermis del fruto. $Y$ para Fusarium sp.,con un micelio generalmente aéreo, abundante, algodonoso y con coloración variable de blanco a rosado durazno [16], con conidióforos variables, escasos y simples o corpulentos cortos con ramificaciones irregulares, conidias hialinas, macroconidias ovoides (Figura 2). Las manchas al pasar el tiempo se hacen numerosas y coalescentes, producen primero el ablandamiento acuoso del fruto y por ultimo su pudrición, que es acelerada por otros microorganismos.

\section{Inhibición de los hongos}

Durante los dos primeros días el tratamiento T2 reveló mayor consumo de $\mathrm{O}_{2}$, mientras que los tratamientos T1 y T4 mantuvieron mayores valores en la 
velocidad de respiración a partir del día 3 respecto a los demás tratamientos a causa del incremento en la actividad metabólica [18], este incremento en la variable de respuesta concuerda con los resultados obtenidos por [19], que encontraron incrementos notorios en la tasa de respiración en tomates sin recubrir lo que atribuyen a la difusión libre de gases como $\mathrm{O}_{2}$ y CO2; el incremento de la tasa de respiración conduce a la maduración propia del fruto.

Es importante mencionar que al final del estudio, los frutos de todos los tratamientos presentaron diferentes niveles de deterioro, en donde una de las razones por las cuales los recubrimientos probablemente no inhibieron completamente el crecimiento de microorganismos son porque al parecer los hongos que inician el deterioro permanecen en el fruto desde etapas tempranas en el cultivo y que solo se desarrollan por cambios fisiológicos dados por la etapa de maduración; y puede deberse a la escasa adherencia de los recubrimientos sobre los frutos no permitió formar una capa uniforme que restringiera el desarrollo de especies fúngicas como ha sido reportado por [20].

Durante de estudio con el paso del tiempo, el ablandamiento de los frutos, las manchas se extienden hasta alcanzar un porcentaje de infección con el T1 entre 24,36 y $43,43 \%$ ya que los tomates no tenían recubrimiento por lo tanto los poros de la epidermis se hacen más suceptibles al ataque por microorganismos [21], en este caso causados por Colletotrichum sp., y Fusarium sp., con el tratamiento T2 el entre 14,16 y $33,23 \%$ de área infectada, presentando menor inhibición de microorganismos, dado que su maduración fue prematura respecto a los demás, lo que se pudo notar de manera cuantitativa en el consumo de $\mathrm{O}_{2}$ y liberación de $\mathrm{CO}_{2}$ y de manera cualitativa en la acelerada aparición de hongos, pues en el día 6 ya se habían desarrollado en algunos frutos (Figura 3); a partir de este momento, el hongo evolucionó

Cuadro 1. Resumen de datos de patogenicidad de Colletotrichum sp. y Fusarium sp., por cada tratamiento utilizado.

\begin{tabular}{|c|c|c|c|c|c|c|c|}
\hline \multirow{2}{*}{ Tratamiento } & \multirow{2}{*}{$\begin{array}{l}\text { Tiempo de } \\
\text { evaluación }\end{array}$} & \multicolumn{3}{|c|}{ Área infectada $\left(\mathrm{cm}^{2}\right)$} & \multicolumn{3}{|c|}{ Área infectada (\%) } \\
\hline & & Max & Med & Min & Max & Med & Min \\
\hline \multirow{6}{*}{ T1 } & $\mathrm{PI}$ & 0 & 0 & 0 & 0 & 0 & 0 \\
\hline & D3 & 12,24 & 4,896 & 2,448 & 24,36 & 9,75 & 4,87 \\
\hline & D6 & 15,02 & 6,008 & 3,004 & 29,90 & 11,96 & 5,98 \\
\hline & D9 & 19,54 & 7,816 & 3,908 & 38,89 & 15,56 & 7,78 \\
\hline & D12 & 20,05 & 8,02 & 4,01 & 39,91 & 15,96 & 7,98 \\
\hline & D15 & 21,82 & 8,728 & 4,364 & 43,43 & 17,37 & 8,69 \\
\hline \multirow{6}{*}{ T2 } & $\mathrm{PI}$ & 0 & 0 & 0 & 0 & 0 & 0 \\
\hline & D3 & 0 & 0 & 0 & 0 & 0 & 0 \\
\hline & D6 & 7,11 & 2,85 & 1,42 & 14,16 & 5,66 & 2,83 \\
\hline & D9 & 14,41 & 5,77 & 2,88 & 28,69 & 11,48 & 5,74 \\
\hline & D12 & 14,92 & 5,97 & 2,98 & 29,70 & 11,88 & 5,94 \\
\hline & D15 & 16,69 & 6,68 & 3,34 & 33,23 & 13,29 & 6,65 \\
\hline \multirow{6}{*}{ T3 } & $\mathrm{PI}$ & 0 & 0 & 0 & 0 & 0 & 0 \\
\hline & D3 & 0 & 0 & 0 & 0 & 0 & 0 \\
\hline & D6 & 5,01 & 2,00 & 1,00 & 9,97 & 3,99 & 1,99 \\
\hline & D9 & 12,31 & 4,92 & 2,46 & 24,50 & 9,80 & 4,90 \\
\hline & D12 & 12,82 & 5,13 & 2,56 & 25,51 & 10,20 & 5,10 \\
\hline & D15 & 14,59 & 5,83 & 2,92 & 29,04 & 11,61 & 5,81 \\
\hline \multirow{6}{*}{ T4 } & $\mathrm{PI}$ & 0 & 0 & 0 & 0 & 0 & 0 \\
\hline & D3 & 0 & 0 & 0 & 0 & 0 & 0 \\
\hline & D6 & 5,97 & 2,39 & 1,19 & 11,89 & 4,76 & 2,38 \\
\hline & D9 & 13,27 & 5,31 & 2,65 & 26,42 & 10,57 & 5,28 \\
\hline & D12 & 13,78 & 5,51 & 2,76 & 27,44 & 10,97 & 5,49 \\
\hline & D15 & 15,55 & 6,22 & 3,11 & 30,96 & 12,38 & 6,19 \\
\hline
\end{tabular}


Figura 1. Características macromorfológicas (anverso), microfotografía y aspecto del Colletotrichum sp en el fruto.

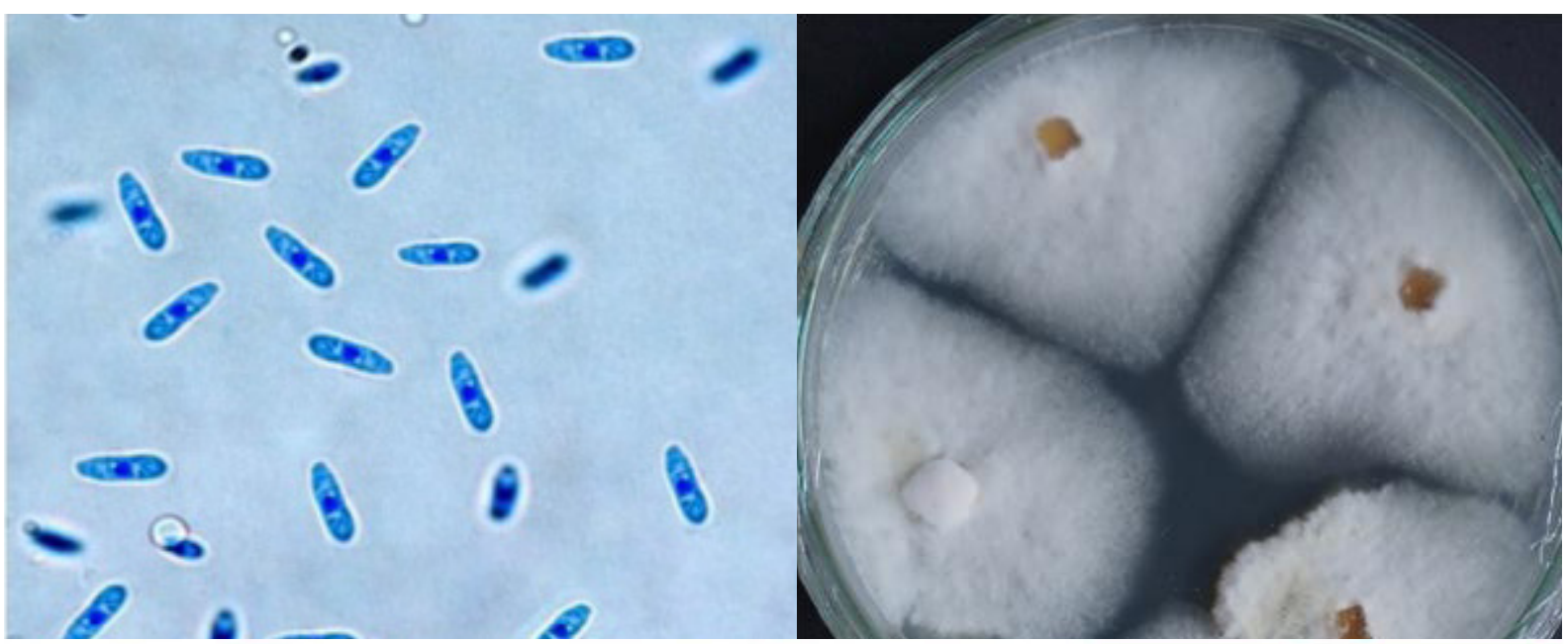

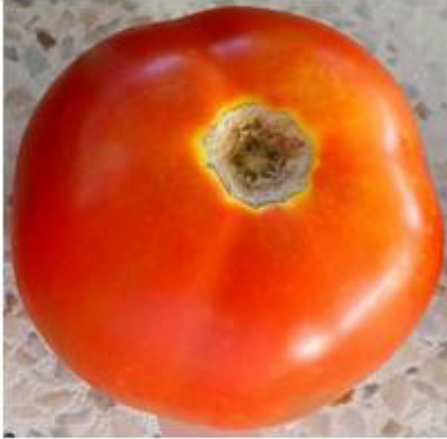

PUNTO INICIAL

DÍA 0

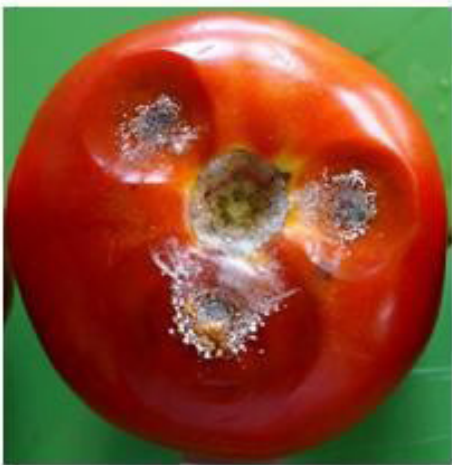

DÍA 9

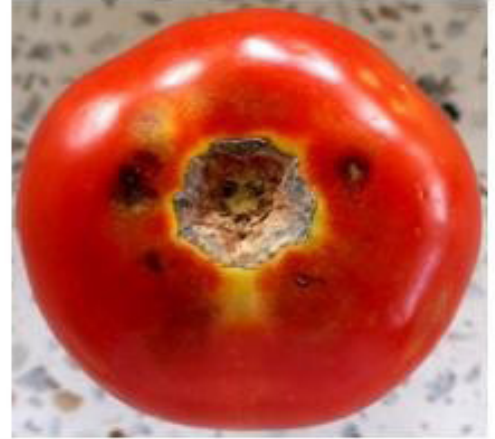

DíA 3

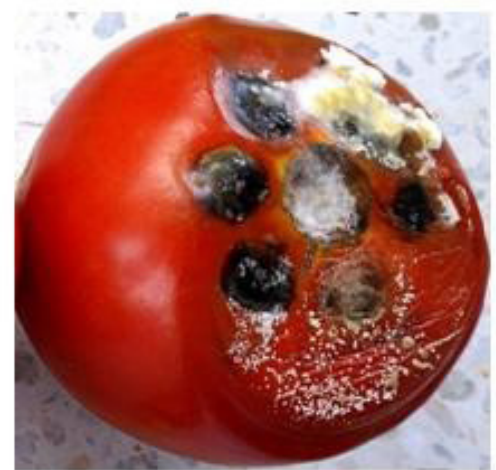

DÍA 12

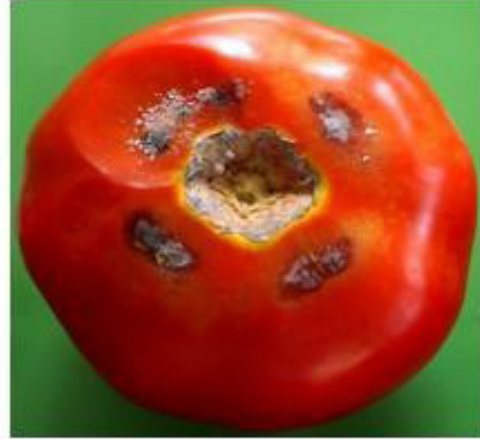

DIA 6

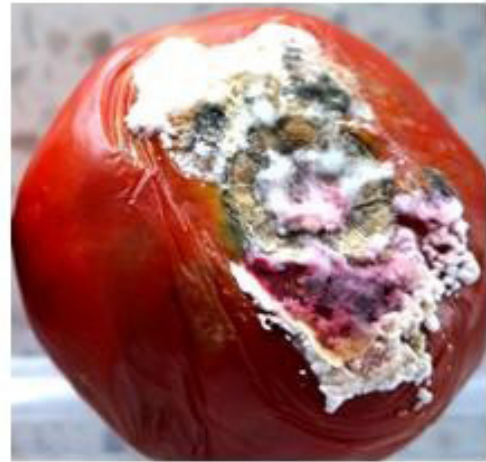

DíA 15 
Figura 2. Características macromorfológicas de Fusarium Sp. (anverso) y Microfotografía.
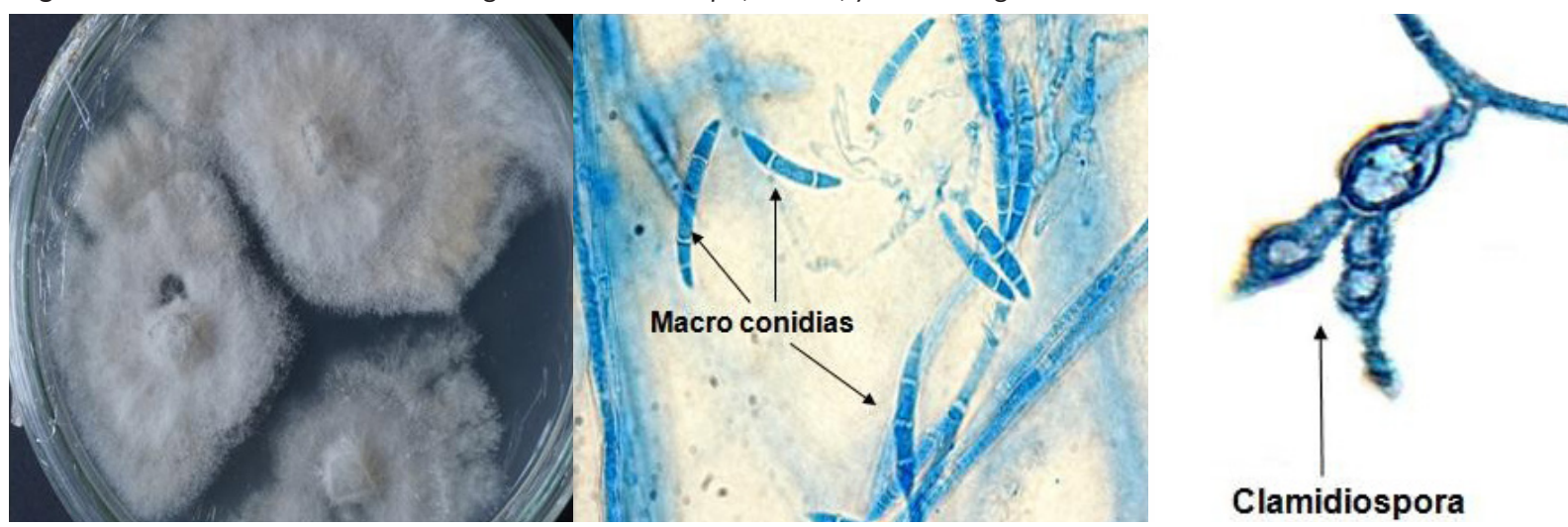

Clamidiospora

hasta desintegrarse en el fruto causando olores desagradables y exudación de líquidos, mientras que los frutos tratados con ácido cítrico fueron atacados tres días después que los otros tratamientos con un porcentaje de área afectada entre 9,97 y $29,04 \%$, puede deberse al potencial inhibitorio del ácido cítrico al degradar en enzimas celulolíticas y pectinolíticas de los hongos [22, 23].

Con el tratamiento el T4 se evidenció un comportamiento similar al de T3, con áreas afectadas entre 4,76 y $12,38 \%$.

\section{Microscopía Óptica de Alta Resolución (MOAR)}

La muestra testigo y la recubierta con almidón nativo presentaron cutícula delgada, de color azul agua marina intenso, células epidérmicas achatadas y parénquima con grosor mayor que el de las células epidérmicas, frente a otros cortes de exocarpo a los cuales se les aplicó recubrimiento con almidón modificado enzimáticamente y con ácido cítrico, en los cuales se generó un ensanchamiento de la cutícula del exocarpo [23], y de la capa de colénquima, debido a que la cutícula no es impermeable al presentar porosidades que facilitan el ingreso de compuestos polares y apolares, lo que permite inferir que pequeñas partes acuosas del recubrimiento penetraron la cutícula provocando el ensanchamiento de la células epidérmicas y colenquimatosas [24]. Los tomates a los cuales se les aplicó recubrimiento de almidón modificado con ácido cítrico, presentaron una apariencia con aumento en el tamaño de las células del exocarpo en forma circular frente a las demás muestras (Figura 4).

Figura 3. Observaciones del día 6: a) Testigo y Tratamiento T2, b) Recubrimiento con almidón modificado con ácido cítrico y Recubrimiento con almidón nativo.

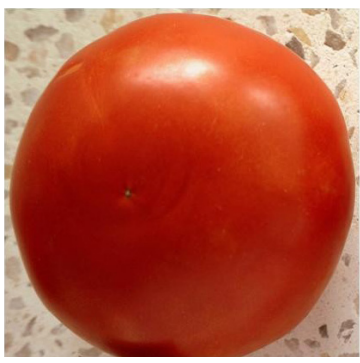

a) Testigo y Tratamiento $\mathrm{T} 2$

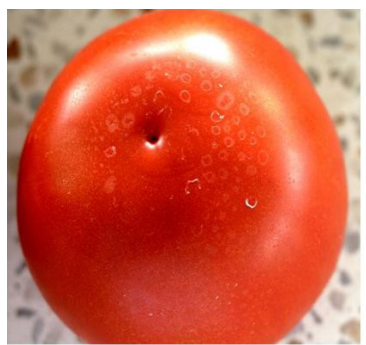

b) Recubrimiento con almidón modificado con ácido cítrico y recubrimiento con almidón nativo

Debido a la falta de estudios que relacionen la introducción de recubrimientos (de almidón de yuca) en células epidérmicas de tomate, se intuye que la modificación (enzimática o por vía ácida), produce una disminución en la viscosidad del almidón, lo que hace más fácil la penetración del recubrimiento hacia el interior de las células epidérmicas [21]. Se encontró una diferencia entre las imágenes del exocarpo de los tratamientos T2 y T3; en este último, la capa de colénquima presentó mayor tamaño con células redondeadas (respecto a T2), lo que significa que a través del mesocarpo se dio una transmisión de componentes presentes en el recubrimiento. 
Figura 4. Imágenes del exocarpo del tomate con diversos recubrimientos.

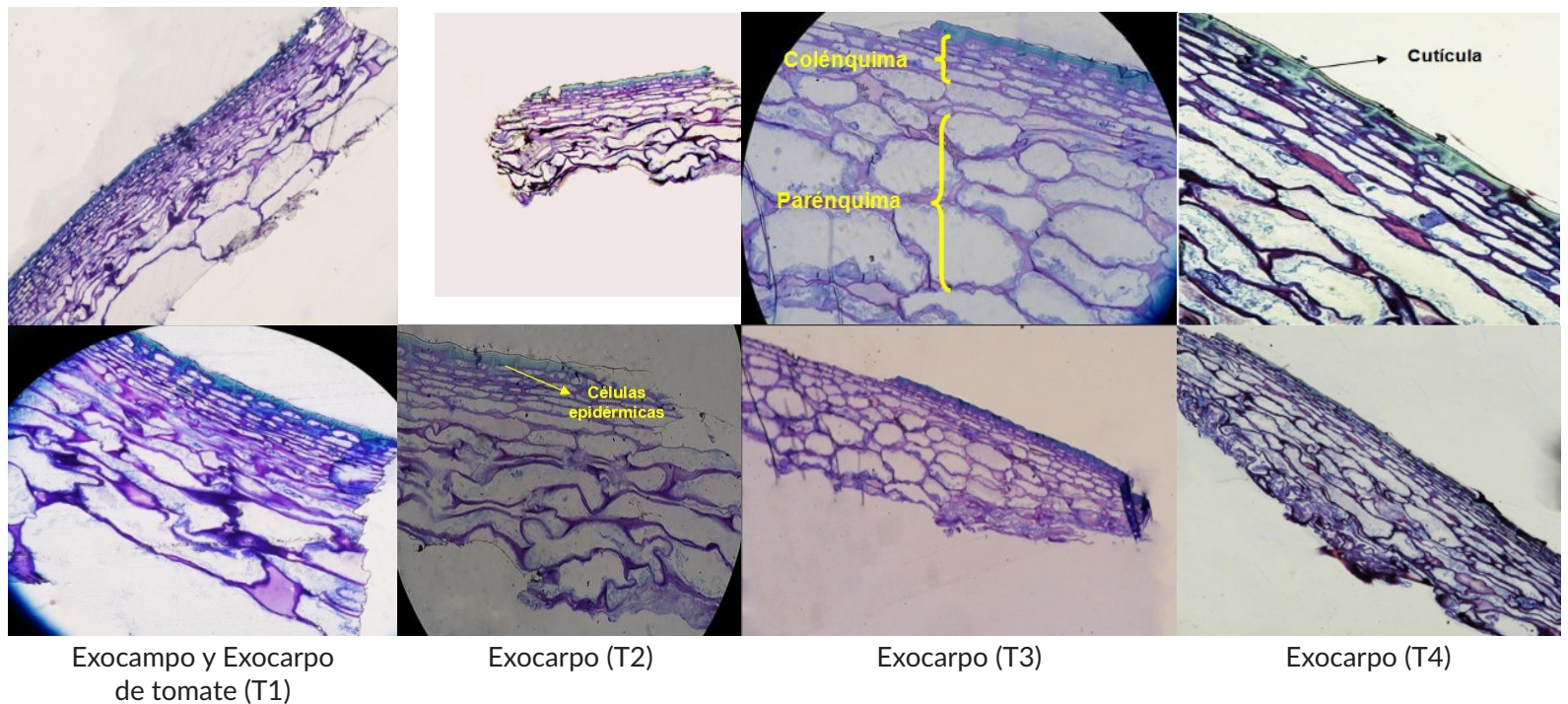

Figura 5. MET del Exocarpo de tomate.

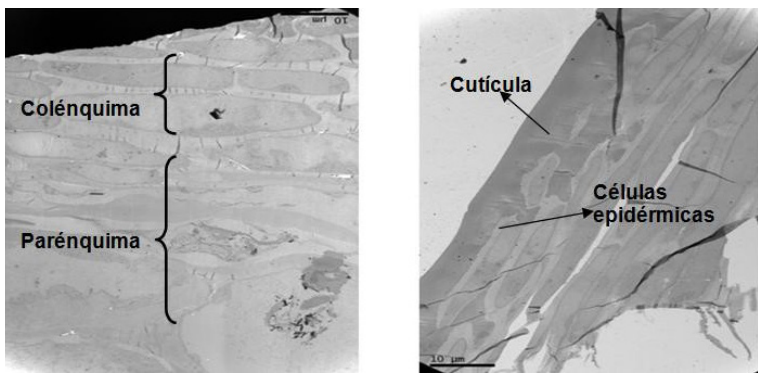

Muestra testigo y con recubrimiento de almidón modificado

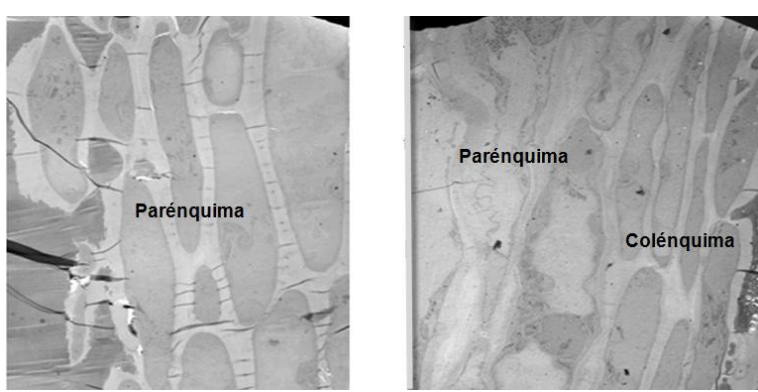

Con recubrimiento de almidón modificado con ácido cítrico y con almidón nativo

\section{Microscopía Electrónica de Transmisión (MET)}

Se obtuvieron imágenes en las que se pudo apreciar la sección de la cutícula y las células epidémicas, corroborando lo observado en las imágenes de MOAR (Figura 5).

\section{CONCLUSIONES}

De forma cualitativa se estableció que los frutos del tratamiento T3 presentaron retraso de 3 días en la maduración y en el ataque por hongos, por lo que se concluye que el ácido cítrico se puede añadir como agente conservante en recubrimientos y no como modificador de almidón para uso en los mismos, dado que se necesita una enorme cantidad para lograr mayor viscosidad.

Con la Microscopía Óptica de Alta Resolución (MOAR) y Microscopía Electrónica de Transmisión (MET), se observaron las diferencias en las células epidérmicas del exocarpo de tomate, siendo el recubrimiento con almidón modificado con ácido cítrico el que produjo mayor ensanchamiento de las células epidérmicas.

\section{AGRADECIMIENTOS}

Los autores expresan su agradecimiento a la Universidad del Cauca por el uso de instalaciones físicas y por el recurso humano vinculado al proyecto.

\section{REFERENCIAS}

[1] ASOCIACIÓN HORTOFRUTÍCOLA DE COLOMBIA (ASOHOFRUCOL). Balance y perspectivas del sector hortofrutícola. Frutas \& Hortalizas, 33(12), 2014, p. 11-17. 
[2] SAN MARTÍN, C., ORDAZ, V., SÁNCHEZ, P., BERYL, M. y BORGES, L. Calidad de tomate (Solanum lycopersicum L.) producido en hidroponia con diferentes granulometrías de tezontle. Agrociencia, 46(3), p. 243-254.

[3] DUSSAN, S., TORRES, C. y REYES, P. Efecto del recubrimiento comestible sobre los atributos físico-químicos de mango Tommy atkins mínimamente procesado y refrigerado. Acta agronómica, 63(3), 2014, p. 1-18. doi:https:// doi.org/10.15446/acag.v63n3.40973.

[4] BARCO, P., BURBANO, A.C., MOSQUERA, S.A., VILLADA, H.S. y NAVIA, D.P. Efecto del recubrimiento a base de almidón de yuca modificado sobre la maduración del tomate. Revista Lasallista de Investigación, 8(2), 2011, p. 96-103.

[5] BONILLA, J.R., HOYOS, J.L. y VILLADA, H.S. Modificación enzimática de almidón de yuca (Manihot esculenta Crantz) para el desarrollo de películas flexibles. Biotecnología en el sector agropecuario y agroindustrial, 12(1), 2014, p. 134-143.

[6] GUTIÉRREZ, T., PÉREZ, E., GUZMÁN, R. and FAMÁ, L. Physicochemical and functional properties of native and modified by crosslinking, dark-cushcush yam (Dioscorea Trifida) and cassava (Manihot Esculenta) starch. Journal of Polymer and Biopolymer Physics Chemistry, 2(1), 2014, p. 1-5. doi: https://- 10.12691/jpbpc-2-1-1

[7] GIOPATO, F. Obtenção e caracterização de amido de mandioca (Manihot esculenta Crantz) modificado com ácido tartárico [Tesis Mestrado em Tecnologia de Alimentos]. Paraná (Brasil): Universidade Tecnológica Federal do Paraná 2015.

[8] MERCADO, J., MADERA, T. y YOCUPICIO, J. Evaluación de un recubrimiento comestible a base de agar y ácido cítrico. Investigación y Ciencia de la Universidad Autónoma de Aguascalientes, 429, 2015, p. 33-39.

[9] ORDOÑEZ, D., ZÚÑIGA, D., HOYOS, J.L., MOSQUERA, S.A. y MOSQUERA, L.P. Efecto de recubrimiento de almidón de yuca modificado y aceite de tomillo aplicado al pimiento (Capsicum annuum). Revista Mexicana de Ciencias Agrícolas, 5(5), 2014, p. 795-805.

[10] SÁNCHEZ, D., CONTRERAS, J., NEVÁREZ, G. y AGUILAR, C. Caracterización de películas comestibles a base de extractos pécticos y aceite esencial de limón Mexicano. C y T A, Journal of Food, 13, 2015, p. 16-25. doi:https://doi.org /10.1080/19476337.2014.904929
[11] RIOJAS, H., GORTÁRES, P., MONDACA, I. Y BALDERAS, J. Aplicación de Tween 80 y D - Limoneno en la biorremediación de suelo contaminado por hidrocarburos. Ide@s CONCYTEG, 6(71), 2011, p. 571-584.

[12] INSTITUTO COLOMBIANO DE NORMAS TÉCNICAS Y CERTIFICACIÓN (ICONTEC). NTC 1103-1 Industrias Alimentarias. Tomate de Mesa. Bogotá (Colombia): 2001.

[13] FALADE, K. and AYETIGBO, O. Effects of annealing, acid hydrolysis and citric acid modifications on physical and functional properties of starches from four yam (Dioscorea spp.) cultivars. Food Hydrocolloids, 43, 2015, p. 529-539. doi.https://doi. org/10.1016/j.foodhyd.2014.07.008

[14] ALVES, T., KLOSOSKI, S. e MONTANHINI, M. Produção e caracterização de amidos de mandioca modificados. Revista Agropecuária Técnica, 36, 2015, p. 58-64.

[15] PAZ, S.P, MOSQUERA S.A. y VILLADA, H.S. Evaluación de la permeabilidad de un recubrimiento elaborado a partir de almidón de yuca nativo y modificado. Vitae, 23(1), 2016, p. 222-225. doi:https://doi.org/10.31910/rudca.v22.n2.2019.1388

[16] SANTACRUZ, C. Caracterización morfológica, patogénica y molecular de especies de colletotrichum spp. causantes de la antracnosis del fruto de ají y pimentón capsicum spp. en el Valle del Cauca [Tesis Magíster en Ciencias Agrarias]. Palmira (Colombia): Universidad Nacional de Colombia, Facultad de Ciencias Agropecuarias, 2013.

[17] PLANA, D., ÁlVAREZ, M., DUEÑAS, F., LARA, R., MOYA, C., FLORIDO, M., y RODRÍGUEZ, J. Caracterización de la mancha solar en frutos de tomate (Solanum lycopersicum) cosechados en Cuba. Cultivos Tropicales, 32(3), 2011, p. 36-41.

[18] HERNÁNDEZ, J. Caracterización físico-química y microbiológica del tomate margariteño (Licopersicum esculentum var. España) y evaluación de la efectividad de tratamientos de pre-envasado para el incremento de su vida comercial a temperatura ambiente (Tesis Doctoral). Córdoba (España): Universidad de Córdoba, 2013.

[19] JIMÉNEZ, E. y DUQUE, J. Efecto de la inclusión de propóleo en el recubrimeinto de almidón de yuca modificado sobre la bacteria Erwinia carotovora causante de la pudrición blanda del tomate de mesa (Solanum Lycopersicum) (Tesis Ingeniería Agroindustrial). Popayán (Colombia): Universidad del Cauca, 2016. 
[20] NAYAK, S. L., SETHI, S., SHARMA, R. R. \& PRAJAPATI, U. (2019). Active Edible Coatings for Fresh Fruits and Vegetables. In Polymers for Agri-Food Applications. Berna (Suiza): Springer Cham, 2019, p. 417-432.

[21] MINUTO, A., GILARDI, G., GULLINO, M.L. and GARIBALDI, A. Increasing severity of attacks of Colletotrichum coccodes on grafted tomatoes. Acta horticulturae, 789, p. 101-106. doi:https:// doi.org.10.17660/ActaHortic.2008.789.12

[22] ZAHID, N., MAQBOOL, M., ALI, A., SIDDIQUI, Y. and BHATTI, Q.A. Inhibition in production of cellulolytic and pectinolytic enzymes of Colletotrichum gloeosporioides isolated from dragon fruit plants in response to submicron chitosan dispersions. Scientia horticulturae, 243, 2019, p. 314-319. doi:https://doi.org/10.1016/j.scienta.2018.08.011

[23] GRANDE TOVAR, C.D., DELGADO-OSPINA, J., NAVIA-PORRAS, D.P., PERALTA-RUIZ, Y., CORDERO, A.P., CASTRO, J.I. and CHAVESLÓPEZ, C. Colletotrichum Gloesporioides inhibition in situ by chitosan-ruta graveolens essential oil coatings: effect on microbiological, physicochemical, and organoleptic properties of guava (Psidium guajava L.) during room temperature storage. Biomolecules, 2019, 9(9), p. 399. Doi:https://doi.org/10.3390/biom9090399.

[24] BLACK-SOLIS, J., VENTURA-AGUILAR, R.I., CORREA-PACHECO, Z., CORONA-RANGEL, M.L., and BAUTISTA-BAÑOS, S. Preharvest use of biodegradable polyester nets added with cinnamon essential oil and the effect on the storage life of tomatoes and the development of Alternaria alternata. Scientia Horticulturae, 245, 2019, p. 65-73. doi: https:// doi.org.co/10.1016/j.scienta.2018.10.004 